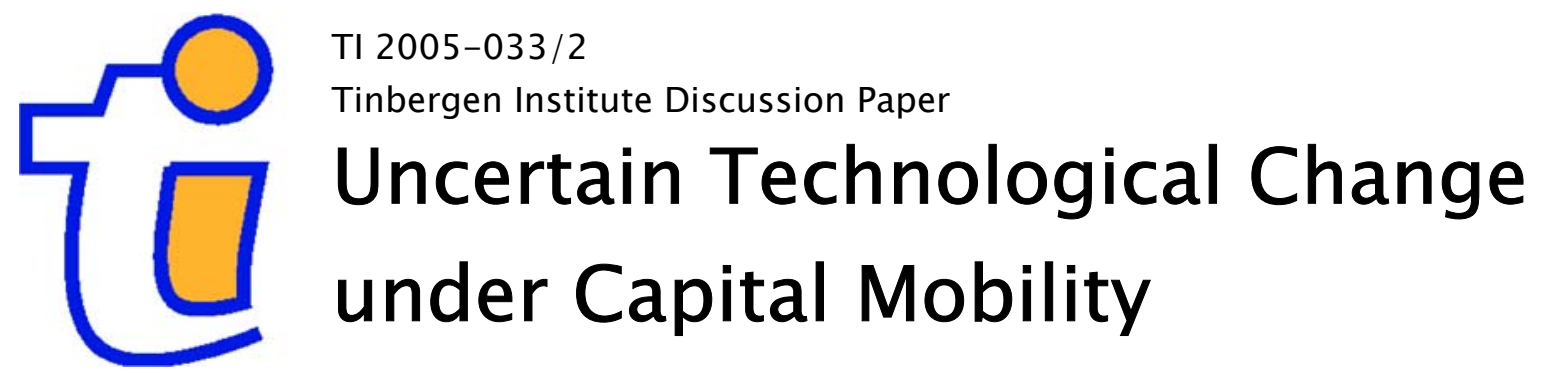

Paul A. de Hek

Faculty of Economics, Erasmus University Rotterdam, and Tinbergen Institute. 


\section{Tinbergen Institute}

The Tinbergen Institute is the institute for economic research of the Erasmus Universiteit Rotterdam, Universiteit van Amsterdam, and Vrije Universiteit Amsterdam.

Tinbergen Institute Amsterdam

Roetersstraat 31

1018 WB Amsterdam

The Netherlands

Tel.: $\quad+31(0) 205513500$

Fax: $\quad+31(0) 205513555$

Tinbergen Institute Rotterdam

Burg. Oudlaan 50

3062 PA Rotterdam

The Netherlands

Tel.: $\quad+31(0) 104088900$

Fax: $\quad+31(0) 104089031$

Please send questions and/or remarks of nonscientific nature to driessen@tinbergen.nl.

Most TI discussion papers can be downloaded at http://www.tinbergen.nl. 


\title{
Uncertain Technological Change under Capital Mobility*
}

\author{
Paul A. de Hek ${ }^{\dagger}$ \\ Erasmus University Rotterdam and Tinbergen Institute
}

\begin{abstract}
The analysis in this paper shows that unpredictable variations in economic productivity may have a positive or negative effect on the average growth rate of output. This theoretical ambiguity result is not solely determined by the value of the elasticity of intertemporal substitution (of consumption) - as is the case in the earlier analyses but depends on two factors. That is, the growth-uncertainty relationship depends on whether returns to scale in knowledge creation are increasing or non-increasing and whether the elasticity of intertemporal substitution (of profits) is higher or lower than some critical value. Empirical studies concerning these two factors indicate that unpredictable variations in economic productivity have a negative effect on the average long-run growth rate.
\end{abstract}

JEL Numbers: O3

Keywords: Long-run growth, Technological change, Uncertainty, Capital mobility, Risk aversion

\section{Introduction}

Although much work has been done in the field of stochastic endogenous growth models (see e.g. King and Rebelo, 1988; King, Plosser and Rebelo, 1988; Obstfeld, 1994; Hopenhayn and Muniagurria, 1996; Wälde, 1999), there are only a few analyses on the influence of uncertainty on (the distribution of) the long-run growth rate. Previous work on economic growth

*Address for correspondence: Paul de Hek, Department of Economics, H7-11, Erasmus University Rotterdam, P.O.Box 1738, 3000 DR Rotterdam, The Netherlands. Tel. +3110-408 1423, e-mail: pdehek@few.eur.nl.

${ }^{\dagger}$ I thank Jean-Marie Viaene for helpful discussions. Financial support from the Netherlands Organisation for Scientific Research (NWO) is gratefully acknowledged. 
under uncertainty has focused on issues like the existence of a limiting distribution for capital and consumption, but has not tried to understand how the distribution of productivity shocks affects growth in the long run.

In an important empirical study Ramey and Ramey (1995) find evidence that economic growth and the volatility of the economic fluctuations are negatively linked. This negative relationship is primarily due to the volatility of the innovations to growth (i.e., of unpredictable changes in the growth rate). This latter measure corresponds closely to the notion of uncertainty. At face value this result seems to contradict those of Kormendi and Meguire (1985) who find that the standard deviation of output growth has a significant positive effect on growth. However, Ramey and Ramey (1995, p.1145) argue that in the regressions of Kormendi and Meguire, the positive effect of the standard deviation may be capturing the effect of predictable movements in growth. In that way, both results are consistent: volatility of the innovations seems to have a negative effect, while volatility in the predicted variable has a positive effect on growth. ${ }^{1}$ Recent studies by Martin and Rogers (2000) and Imbs (2002) largely confirm the result that countries with higher volatility grow (conditionally) at a lower rate.

Investments in research and development (R\&D) or, more generally, investments in the creation of knowledge are the driving force behind the advancement of the technology. More investments will generally lead to a higher rate of technological change, and, consequently, to higher economic growth. However, the return to these investments is not known in advance, that is, the productivity of knowledge creation is uncertain. This creates a link between uncertainty and (long-run) growth. In the present paper, uncertainty derives from randomness in the productivity of $\mathrm{R} \& \mathrm{D}$. In general, one part of uncertainty is due to individual, firm-specific (idiosyncratic) uncertainty, while the other part arises from economy-wide (common) shocks, which have the same impact on all firms. Here, the analysis will focus on common shocks ${ }^{2}$, such as technology and policy shocks. The objective of this paper is, then, to find out the nature (positive or negative) of the link between growth and aggregate uncertainty and to identify the main factors that determine this nature.

Concerning the theoretical literature on this topic, both Jones, Manuelli and Stacchetti (1999) and De Hek (1999) show that the relationship between volatility in macroeconomic productivity and mean growth can be either

\footnotetext{
${ }^{1}$ See also Guiso and Parigi (1999) and Aizenman and Marion (1999) who find a negative relationship between volatility and (private) investment.

${ }^{2}$ Schankerman (2001) finds that idiosyncratic shocks do not account for much (approximately $25 \%$ ) of the variation in investment decisions. Nearly $75 \%$ of the microvariance is due to heterogeneity in micro level responses to aggregate (common) shocks.
} 
positive or negative. The curvature of the utility function is identified as a key parameter that determines the sign of the relationship. In a recent paper Blackburn and Pelloni (2001) investigate the relationship between growth and volatility in learning-by-doing economies. They find that the correlation between long-term growth and short-term volatility depends on the source of stochastic fluctuations and the functioning of the labor market. As regards the former, long-run growth is negatively related to the volatility of (nonneutral) nominal shocks, but positively related to the volatility of real shocks.

The present analysis uses a model of endogenous technological change where sustained growth stems from intentional investments in R\&D from profit-maximizing, risk-averse firms. Physical capital is assumed to be fully mobile, while labor is assumed to be immobile. Uncertainty derives from the productivity of investments in R\&D. The main result of this analysis is that the relationship between long-run growth and uncertainty (on the productivity of knowledge creation) depends on two main factors - increasing or non-increasing returns to scale in knowledge creation and a high or low value of the elasticity of intertemporal substitution (of a firms' profits). Empirical studies on the returns to scale in knowledge creation ("non-increasing") and the value of the elasticity of intertemporal substitution ("higher than the critical value") indicate a negative relationship between long-run growth and uncertainty regarding the productivity of knowledge creation.

Hence, this study identifies a new factor - the returns to scale in the research sector - which influences the growth-uncertainty relationship. Moreover, while Jones, Manuelli and Stacchetti (1999) quantitatively find a positive relationship between growth and uncertainty ${ }^{3}$, the present analysis establishes a verifiable critical value of the elasticity of intertemporal substitution, implying a negative relationship between growth and uncertainty, consistent with the empirical evidence cited above.

\section{The Model}

The model that will be developed in this section is based on the models of endogenous technological change of Romer (1990) and Aghion and Howitt (1998, Ch. 3). The main difference with these models is that in the present model, instead of having a separate research sector, research is being undertaken by the intermediate-good producers. Research by a firm enhances the firm's own state of the technology (and has a positive external effect on the other firms' states of the technology). This setting allows us to find the

\footnotetext{
${ }^{3}$ De Hek (1999) makes no prediction concerning the most likely nature of the relationship.
} 
effect of higher uncertainty in the productivity of investments in $R \& D$ on the growth rate through the optimal choices, concerning capital and (skilled) labor, of the intermediate-good producers.

\subsection{Technology}

The consumption-capital good in the economy, final output $Y$, is produced according to

$$
Y_{t}=L_{t}^{1-\beta} \int_{0}^{1} A_{i t} x_{i t}^{\beta} d i
$$

where $x_{i t}$ is the quantity of intermediate $\left(\right.$ or capital ${ }^{4}$ ) good i, $L_{t}$ is the quantity of labor employed to produce final output and $A_{i t}$ is an index for the technology or knowledge in firm (or sector) i. At each date, the representative final-output firm decides how much of each intermediate good it rents from the producers of those goods. Maximization of its profits implies that the price (or rental rate) $p_{i t}$ of intermediate good $\mathrm{i}$ is given by

$$
p_{i t}=\beta L_{t}^{1-\beta} A_{i t} x_{i t}^{\beta-1}, \forall i \in[0,1] .
$$

The wage rate $w_{L, t}$ of (skilled) labor used in the final-output sector is equal to its marginal product,

$$
w_{L, t}=\int_{0}^{1}(1-\beta) L_{t}^{-\beta} A_{i t} x_{i t}^{\beta} d i .
$$

Each intermediate good is produced by a firm that has an infinitely-lived patent on that design (or can in some other way effectively prevent other competitors from entering the market, without affecting the profit maximization). Due to this monopoly power an intermediate firm can devote resources, i.e., labor, to research and development $(\mathrm{R} \& \mathrm{D})$, which enhances the state of the technology of that firm. A higher state of the technology might be seen as an improvement of the quality of the firm's product and implies higher profits. The intermediate sector uses labor to conduct research. Labor or human capital $^{5}$ in sector i is denoted by $h_{i t}$. Average or total human capital used to conduct research is then given by $H_{t}=\int_{0}^{1} h_{j t} d j$. The total labor force in the economy is fixed and set to 1 , i.e., $L_{t}+H_{t}=1$ for all t.

\footnotetext{
${ }^{4}$ Intermediate goods and capital (goods) are used interchangeably throughout the paper.

${ }^{5}$ In this paper, the amount of human capital used in sector $\mathrm{i}, h_{i t}$, is defined to be the amount of labor used in sector i, $l_{\text {Ait }}$, times the (constant) skill level, $\bar{h}$. Normalizing $\bar{h}$ to 1 implies that $h_{i t}=l_{\text {Ait }}$.
} 
To produce intermediate goods at the rate $x_{i t}$, the firm in sector $i$ requires the use of $A_{i t} x_{i t}$ units of capital. We assume throughout this paper full international capital mobility, while labor (human capital) is assumed to be immobile. Thus the interest rate $r$ is exogenously given and is equal to the international interest rate. The per period profit of an intermediate-good producer is therefore given by

$$
\pi_{i t}=p_{i t} x_{i t}-r A_{i t} x_{i t}-w_{H, t} h_{i t},
$$

where $w_{H, t}$ is the wage rate of human capital.

Suppose that technology or knowledge evolves according to

$$
A_{i, t+1}=\left(1+\eta_{t+1} h_{i t}^{\gamma} H_{t}^{\theta}\right) A_{i t},
$$

where $\gamma>0$ is a returns-to-scale parameter, $\theta>0$ a parameter controlling the spill-over effect of average (or total) human capital, $H_{t}=\int_{0}^{1} h_{j t} d j$, and $\eta$ a random variable representing the productivity of human capital in the accumulation of knowledge. In every period, $\eta$ may take any value on some interval $I$. As a result, the return to research is uncertain. The probability distribution of the return is, however, known and fixed. More formally, assume that the sequence of shocks $\left\{\eta_{t}\right\}$ satisfies:

$\left\{\eta_{t}\right\}$ is a sequence of independently and identically distributed (i.i.d.) random variables with probability distribution $\mu$ and support $I=[\underline{\eta}, \bar{\eta}], \bar{\eta}>\underline{\eta}>0$.

Clearly, more (less) uncertainty is associated with higher (lower) variability. (For a formal definition of variability see Rothschild and Stiglitz, 1970). To determine the effect of changing the variability on the expectation of a function of the random variable, the following result by Rothschild and Stiglitz (1971) is very useful:

Given that $Y$ is more variable than $X, E f(X)>(\geq) E f(Y)$ if $f$ is strictly (weakly) concave, while $E g(X)<(\leq) E g(Y)$ if $g$ is strictly (weakly) convex.

Therefore, to determine the effect of increasing (or decreasing) variability on $E f(X)$, it is sufficient to find out whether $f($.$) is strictly concave or strictly$ convex. E.g. if $f(X)$ is strictly concave, increasing the variability of $X$ leads to a decrease in the expectation of $f(X)$.

One line of reasoning suggests that, since all firms are owned by the consumers (possibly represented by the representative consumer), the utility 
functions of the consumers should determine how firms behave. That is, firms should make their choices to maximize the expected utility (of consumption) of the owners of the firm. However, according to a second line of reasoning, if the owners delegate the management of the firm to a manager, you could argue that the manager does not know the utility functions of the owners of the firm. Suppose for example that the ownership shares held in the firms can be traded among the consumers, either nationally or internationally. Then, if consumers (foreign or domestic) differ with respect to their utility functions, the managers of the firms will not know which (kind of) consumers own their firm. In that case it seems natural for the manager to maximize the expected discounted stream of profits or, to incorporate possible risk aversion, the expected discounted stream of the utility of profits ${ }^{6}$.

Adopting the second line of reasoning ${ }^{7}$, the intertemporal expected profit maximization problem of an intermediate-good producer is given by:

$$
\begin{gathered}
\max E \sum_{t=0}^{\infty} \delta^{t} \frac{\pi_{i t}^{1-\sigma_{f}}-1}{1-\sigma_{f}} \\
\text { s.t. } A_{i, t+1}=\left(1+\eta_{t+1} h_{i t}^{\gamma} H_{t}^{\theta}\right) A_{i t},
\end{gathered}
$$

where $E$ is the expectation operator, $\delta \equiv 1 /(1+r)$ the discount factor, with $r$ representing the interest rate, and $\pi_{i t}$ is given by equation (4). The parameter $\sigma_{f} \in[0, \infty)$ reflects both a measure of risk aversion and the reciprocal of the elasticity of intertemporal substitution. Notice that this set-up includes the 'standard case' of risk neutrality (and an infinite elasticity of intertemporal substitution), which occurs if $\sigma_{f}=0$. Notice that utility is not well-defined if profits are nonpositive in any period. As shown in appendix 5.2, profits are positive (negative) if and only if $h_{t}<(>) \beta /(1+\beta)$. This implies that, regardless of its utility function, an intermediate-good producer will never employ more (or just as much) labor than the critical level, since this will yield negative (or zero) profits independent from the shocks. ${ }^{8}$

Returns on investment in $\mathrm{R} \& \mathrm{D}$ are uncertain. In each period the impact of research on each firm's stock of knowledge is randomly determined. Since

\footnotetext{
${ }^{6}$ In the literature on the theory of the firm under uncertainty, the assumption that the firm maximizes the expected utility of profits is widely used. See e.g. Sandmo (1971) and Viaene and Zilcha (1998).

${ }^{7}$ A short exposition of the first line of reasoning is given in Appendix 5.5.

${ }^{8}$ Another drawback resulting from this specific utility function concerns the fact that at zero profit marginal utility is infinite. However, as explained in the text, this situation will not arise. On the contrary, profits will grow larger and larger over time (see equation 12), implying that this feature of the utility function is not driving any of the results. The apparent advantage of this specific utility function is that it produces an analytical solution.
} 
$\eta$ is assumed to be independent from $i$, this specification of the uncertainty implies that the shocks are economy wide, i.e., the same for each firm. Therefore, the riskiness of the investments in $R \& D$ is the result of changes in the economic climate, e.g., induced by technology or policy shocks.

In maximizing the expected discounted stream of profits, the firm knows the demand for its product as given by equation (2). Therefore, replacing $p_{i t}$ in the maximization problem with the right-hand side of equation (2) and differentiating with respect to the two choice variables $x_{i t}$ and $h_{i t}$ leads to the first-order conditions. These two conditions can be written as

$$
\begin{gathered}
x_{i t}=\left(\frac{r}{\beta^{2}}\right)^{\frac{1}{\beta-1}} L_{t}, \\
\pi_{i t}^{-\sigma_{f}} w_{H, t}=E\left[\delta \pi_{i, t+1}^{-\sigma_{f}} \eta_{t+1} \gamma h_{i t}^{\gamma-1} H_{t}^{\theta} A_{i t} \beta(1-\beta) L_{t+1}^{1-\beta} x_{i, t+1}^{\beta}\right] .
\end{gathered}
$$

It is assumed that the transversality condition, as given in the appendix, holds. Moreover, profits are assumed to be positive (see the appendix for the associated restriction on the optimal level of human capital). Let $A_{t}$ denote the average productivity parameter across all firms at date $t: A_{t} \equiv \int_{0}^{1} A_{i t} d i$. Because each sector $i$ uses $A_{i t} x_{i t}$ units of capital, the total capital stock (measured in forgone consumption) is equal to $K_{t} \equiv \int_{0}^{1} A_{i t} x_{i t} d i$. According to equation (7), all firms produce the same amount at any given time: $x_{i t}=$ $x_{t}=K_{t} / A_{t}$ for all $i$. Next, suppose that initially at $t=0$ every firm has the same productivity, that is, $A_{i 0}=A_{0}$ for all $i$, which implies that $A_{i t}=A_{t}$ for all $i$. Then equation (8) allows us to have $h_{i t}=h_{t}$ for all $i$, which, in turn, implies that $H_{t}=h_{t}$. As a result, the aggregate technology (1) can now be expressed in the simpler form

$$
Y_{t}=A_{t} x_{t}^{\beta} L_{t}^{1-\beta}
$$

\section{$2.2 \quad$ Preferences}

Assume that consumers behave as if they maximize their expected value of lifetime utility. Consumers are heterogeneous in the sense that they differ in their time preference, $\rho_{j}$, and their elasticity of intertemporal substitution, $\sigma_{j}$. The objective of agent $j$, then, is to select consumption and savings to maximize the expected value of his lifetime utility:

$$
\begin{gathered}
\max E \sum_{t=0}^{\infty}\left(\frac{1}{1+\rho_{j}}\right)^{t} \frac{c_{j, t}^{1-\sigma_{j}}-1}{1-\sigma_{j}} \\
\text { s.t. } b_{j, t+1}=(1+r) b_{j, t}+w_{L, t} L_{j, t}+w_{H, t} h_{j, t}+s_{j} \pi_{t}-c_{j, t},
\end{gathered}
$$


where $c_{j, t}$ is consumption and $b_{j, t}$ represents assets. The agent's sources of income are interest on his stock of assets $r b_{j, t}$, wage income $w_{L, t} L_{j, t}+w_{H, t} h_{j, t}$ and his share $s_{j}$ of profits $\pi_{t}=\beta Y_{t}-r K_{t}-w_{t} h_{t}$. Maximization with respect to consumption and savings implies that the optimal path of consumption follows the Euler equation,

$$
c_{j, t}^{-\sigma_{j}}=E\left[c_{j, t+1}^{-\sigma_{j}}\right] \frac{1+r}{1+\rho_{j}} .
$$

The associated transversality condition, which is assumed to be satisfied, is given in the appendix.

\subsection{Equilibrium}

In equilibrium, the wage rate in the intermediate sector should equal the wage rate in the final-output sector, i.e., $w_{H, t}=(1-\beta) L_{t}^{-\beta} A_{t} x_{t}^{\beta}$. Furthermore, as the total amount of labor present in the economy is normalized to 1 , the time allocation restriction reads $L_{t}+h_{t}=1$. Due to the presence of shocks, the notion of balanced growth needs adjustment. Therefore, instead of a constant growth rate the analysis here focuses on a constant expected growth rate. On this balanced expected-growth path (BEGP) the levels of the intermediate goods and labor are constant. This implies that the per period profit grows with the technology, that is,

$$
\pi_{t+1}=\pi_{t}\left(1+\eta_{t+1} h_{t}^{\gamma+\theta}\right)
$$

Incorporating these considerations in equation (8) leads to the BEGP research condition,

$$
E\left(\beta \gamma(1-h) h^{\gamma+\theta-1} \frac{\eta_{t+1}}{(1+r)\left(1+\eta_{t+1} h^{\gamma+\theta}\right)^{\sigma_{f}}}\right)=1 .
$$

The left-hand side of this equation gives the ratio of the return to an additional unit of skilled labor over the cost of an additional unit of skilled labor, on the BEGP. Given the probability measure of $\eta$, the intermediate producers choose the optimal amount of time spent on research, $\bar{h}$, according to above equation, which determines the rate of technological change,

$$
g_{A, t}=1+\eta_{t+1} \bar{h}_{t}^{\gamma+\theta} .
$$

On the BEGP, $x, L$ and $h$ are determined by the three conditions given by equations (7) and (13) and the time allocation restriction. Additionally, 
it is assumed that the solution to this set of equations also satisfies the transversality condition associated with the optimization problem. See the appendix for the exact condition.

Since the inputs $x$ and $L$ in the production function are constant along the BEGP, the growth rate of output is equal to the rate of technological change:

$$
g_{Y, t}=g_{A, t}
$$

\section{The effect of uncertainty on growth}

\subsection{The growth rate of output}

The effect of higher volatility of the shock $\eta$ on the optimal choice of $h$ depends on the functional form of the BEGP research condition regarding the shock $\eta$ and the variable $h$. The first step in finding the effect of more uncertainty on the growth rate of output is to determine the effect of a higher volatility of $\eta$ on the left-hand-side of equation (13), which will be denoted by $E(\Phi)$. It turns out (see Proposition 1 below) that $\Phi$ is a concave function of $\eta$, a higher volatility of $\eta$ has a negative effect on the expectation of $\Phi$.

Second, the effect of a smaller $E(\Phi)$ on the equilibrium value of $h$ depends on the functional form of $E(\Phi)$ as a function of $h$. If $\gamma+\theta \leq 1$, it is easy to see that $E(\Phi)$ is a decreasing function of $h$, as depicted in figure 1. A higher volatility, which decreases $E(\Phi)$ as a function of $h$, then leads to a smaller level of research. On the other hand, if $\gamma+\theta>1, E(\Phi)$ as a function of $h$ is hump-shaped. This implies that there are two equilibrium values of $h$, a "low research level equilibrium" and a "high research level equilibrium" (that is, if the maximum of $E(\Phi)$ is higher than 1). See figure 2 for an example of this situation. There will actually be more time spent on research due to more uncertainty if the economy is in the low level equilibrium, as opposed to less research time in the high level equilibrium.

What is the effect of a change in the time spent on research on the growth rate of the economy? A reduction in the time spent on research, for example, implies that the expectation of $g_{A}$ decreases, which, in turn, implies that the growth rate of the economy, $g$, will be smaller on average. More formally, consider the two probability measures $\mu$ and $\mu^{+}$, where $\mu^{+}$is more uncertain than $\mu$, that is, it has the same mean but a higher volatility. Then the average growth rate under $\mu^{+}$is smaller than the average growth rate under $\mu$ for almost any sequence of realizations of $\eta$; i.e., it occurs almost surely. The effect of uncertainty on the time spent on research and the average long-run growth rate is summarized in the next proposition. 
Proposition 1 Let $0<\sigma_{f}<2 \frac{1+g_{A}(\bar{\eta})}{g_{A}(\bar{\eta})}-1$. (A). If $\gamma+\theta \leq 1$, then more uncertainty leads to (i) less time spent on research and (ii) a smaller growth rate of output on average. (B). If $\gamma+\theta>1$, there may exist two equilibria. Then more uncertainty leads to (i) more (less) time spent on research and (ii) a higher (smaller) growth rate of output on average if the economy is in the low (high) research level equilibrium.

Proof. See Appendix.

The effect of uncertainty on the path of final output is as follows. For example in case (A) of Proposition 1, more uncertainty leads to less labor used in research and therefore to more labor used in the production of final output. Equation (7), then, shows that the amount of every capital good increases. This implies, by equation (1), that final output increases initially. However, since the growth rate of output has fallen, at some point in time the new path of final output will lie below the initial path. Thus in the long-run, final output is negatively influenced by uncertainty (that is, in case (A) of Proposition 1).

In the previous analysis, the negative effect of uncertainty on output growth could be shown under two restrictions. The first restriction puts an upperbound on $\sigma_{f}$, the reciprocal of the elasticity of intertemporal substitution (of the profits of the intermediate-good producers) as well as a measure of risk aversion. Even if $g_{A}$ under the best shock is as high as $20 \%$, the restriction requires $\sigma_{f}$ to be less than 11 . This means that this restriction will certainly be satisfied if the firms act as if they were close to risk neutral. (However, if firms behave in a strict risk-neutral manner, uncertainty will have no effect on the time spent on research and, hence, on the expected growth rate.) Moreover, even if the firms have similar attitudes towards risk and intertemporal substitution as households, estimates of $\sigma_{f}$ (and hence of $\sigma$ ) usually indicate that its value is roughly between 1 and 7 (see e.g. Gertner, 1993; Metrick, 1995; Beetsma and Schotman, 2001; Guvenen, 2002; Vissing-Jørgenson, 2002). ${ }^{9}$

The second restriction is that there are no increasing returns to R\&D; i.e., $\gamma+\theta \leq 1$. The presence of constant or decreasing returns seems a fairly realistic assumption, which is confirmed by recent empirical evidence. For example, Dinopoulos and Thompson $(1996,2000)$ estimate versions of Romer's model of endogenous technological change (Romer, 1990) and find positive, but decreasing, returns to R\&D. Similar results are found in Hall, Griliches and Hausman (1986), Kortum (1993) and Thompson (1996).

\footnotetext{
${ }^{9}$ On the contrary, very high values of $\sigma$ are found by Hall (1988) and implied by evidence provided by the equity premium puzzle (see e.g. Campbell et al., 1997).
} 
The intuition behind the finding that the nature of the effect of uncertainty on the time spent on research - positive or negative - depends on the parameter $\sigma$ draws on the fact that this parameter represents both risk aversion and the elasticity of intertemporal substitution. The fact that firms are risk averse implies that higher uncertainty reduces the return on investment (in skilled labor) in terms of utility. This affects the amount of investment positively or negatively depending on the relative strenghts of the income and substitution effects. A relatively small $\sigma$, for example, implies that the substitution effect dominates the income effect, inducing a positive effect on investment (i.e., the time spent on research).

\subsection{The growth rate of consumption}

Due to the international capital market, the growth rates of output and consumption differ. Although individual consumption levels and growth rates differ across consumers, as denoted by the subscript $j$, the nature of the effect - positive or negative - does not depend on these differences. As a result, we suppress the subscripts in the following analysis. To determine the effect of uncertainty on the long-run growth rate of consumption, we insert $c_{t+1}=\left(1+g_{c, t+1}\right) c_{t}$ into the Euler equation (11) to get

$$
c_{t}^{-\sigma}=E\left[g_{c, t+1}^{-\sigma} c_{t}^{-\sigma}\right] \frac{1+r}{1+\rho},
$$

which implies that

$$
E\left[g_{c}^{-\sigma}\right]=\frac{1+\rho}{1+r}
$$

Using a second-order Taylor series expansion around $E\left[g_{c}\right], E\left[g_{c}^{-\sigma}\right]$ can be approximated by

$$
E\left[g_{c}^{-\sigma}\right]=E\left[g_{c}\right]^{-\sigma}+\frac{1}{2} \sigma(\sigma+1) E\left[g_{c}\right]^{-(\sigma+2)} \operatorname{var}\left(g_{c}\right),
$$

where $\operatorname{var}\left(g_{c}\right)$ is the variance of the growth rate of consumption. Since consumption depends on the income of the consumers, which in turn depends on the state of the technology, consumption depends on the shock $\eta$. This implies that a higher variability of the shock leads to more variable consumption and, hence, to a more variable growth rate of consumption. Thus, more uncertainty regarding the shock implies a higher $\operatorname{var}\left(g_{c}\right)$. Since, according to equation (17), $E\left[g_{c}^{-\sigma}\right]$ is constant, equation (18) shows that an increase in $\operatorname{var}\left(g_{c}\right)$ will be accompanied with an increase in $E\left[g_{c}\right]$. Therefore, from this analysis we may conclude that, due to more uncertainty, the growth rate of consumption will on average be higher. 
This result - that more uncertainty implies a higher average growth rate of consumption - is driven by the consumers' precautionary saving motive. Due to this motive consumers save more in more uncertain circumstances in order to ensure themselves against 'bad shocks'. Naturally, these higher savings lead to a higher growth rate. The technical reason for the existence of a precautionary saving motive is the fact that the marginal utility is convex. This convexity implies that the negative consequence, in terms of utility, of a bad shock dominates the positive consequence of a similar (in size) good shock.

\section{Conclusion}

The analysis in this paper shows that unpredictable variations in economic productivity may have a positive or negative effect on the average growth rate of output. This confirms the results of earlier papers on this subject. However, this analysis adds two new elements. First, physical capital is assumed to be fully mobile, allowing capital to flow freely between economies. This is in contrast with the earlier closed-economy models. Second, the theoretical ambiguity result is not solely determined by the value of the elasticity of intertemporal substitution (of consumption) - as is the case in the earlier analyses - but depends on two factors. That is, the relationship between unpredictable variations (uncertainty) in economic productivity and economic growth depends on whether returns to scale in knowledge creation are increasing or non-increasing and whether the elasticity of intertemporal substitution (of profits) is higher or lower than some critical value.

Both factors have been studied in the empirical literature. First, empirical studies on the returns to scale in knowledge creation (R\&D) indicate that these returns are decreasing. Second, based on empirical analyses on the elasticity of intertemporal substitution and given the critical value as implied by the rate of technological change (under the best possible shock), it is most likely that the value of the elasticity of intertemporal substitution is higher than the critical value. Together these two results imply that unpredictable variations in economic productivity have a negative effect on the average long-run growth rate. 


\section{Appendix}

\subsection{Transversality conditions}

The transversality condition of the intermediate-good producer's optimization problem is given by

$$
\lim _{t \rightarrow \infty} E \delta^{t} \pi_{t}^{-\sigma_{f}} A_{t+1}=0
$$

The transversality condition of the consumer's optimization problem is given by

$$
\lim _{t \rightarrow \infty} E\left(\frac{1}{1+\rho}\right)^{t} c_{t}^{-\sigma} b_{t+1}=0 .
$$

\subsection{Restriction for " $\pi>0 "$}

The one-period profit of an intermediate-good producer can be written as

$$
\begin{aligned}
\pi_{t} & =\beta L_{t}^{1-\beta} A_{t} x_{t}^{\beta}-\beta^{2} L_{t}^{1-\beta} A_{t} x_{t}^{\beta}-(1-\beta) L_{t}^{-\beta} A_{t} x_{t}^{\beta} h_{t}, \\
& =\beta(1-\beta) Y_{t}-(1-\beta) Y_{t} \frac{h_{t}}{L_{t}} .
\end{aligned}
$$

This equation implies that $\pi_{t}>0$ iff $h_{t}<\beta L_{t}=\beta\left(1-h_{t}\right)$. Hence, profit $\pi_{t}$ is positive if and only if $h_{t}<\beta /(1+\beta)$. If $\beta=1 / 3$, this implies that $h_{t}<1 / 4$.

\subsection{Proof of proposition 1}

This proof consists of proving the two steps taken in the text prior to the proposition. First, we have to prove that $G(\eta) \equiv \eta /\left(1+\eta h^{\gamma+\theta}\right)^{\sigma_{f}}$ is a concave function of $\eta$. Let us write $G(\eta)=\eta /(1+b \eta)^{\sigma_{f}}$, with $b=h^{\gamma+\theta}$. Differentiating $G($.$) with respect to \eta$ shows that $\partial G / \partial \eta=\left(1+\left(1-\sigma_{f}\right) b \eta\right) /\left((1+b \eta)^{1+\sigma_{f}}\right)$. Differentiating again with respect to $\eta$ yields

$$
\frac{\partial^{2} G(\eta)}{\partial \eta^{2}}=\frac{(1+b \eta)\left(1-\sigma_{f}\right) b-\left(1+\left(1-\sigma_{f}\right) b \eta\right)\left(1+\sigma_{f}\right) b}{(1+b \eta)^{2+\sigma_{f}}} .
$$

From this we can conclude that $\partial^{2} G / \partial \eta^{2}<0$ if and only if $1+\sigma_{f}<2(1+$ $b \eta) / b \eta$. Hence, $G(\eta)$ is (strictly) concave for all $\eta \in[\underline{\eta}, \bar{\eta}]$ iff

$$
1+\sigma_{f}<\min _{\eta \in[\underline{\eta}, \bar{\eta}]}\left[2 \frac{1+b \eta}{b \eta}\right]=2 \frac{1+g_{A}(\bar{\eta})}{g_{A}(\bar{\eta})}
$$

since $b=h^{\gamma+\theta}$. Hence, by Lemma 1 , a higher volatility of $\eta$ decreases $E(\Phi)$. 
Define the function $F$ as follows: $F(h)=m \eta(1-h) h^{\gamma+\theta-1} /\left(1+\eta h^{\gamma+\theta}\right)^{\sigma_{f}}$, with $m=\beta \gamma /(1+r)$. If $\gamma+\theta \leq 1$, it is evident that $F(h)$ is decreasing in $h$. As a result, $E(\Phi)$ is decreasing in $h$. If $\gamma+\theta>1$, numerical simulations indicate that $F(h)$ is hump-shaped. Thus if the maximum of the function is high enough there exist two equilibria.

The first step implies that a higher volatility of $\eta$ decreases $E(\Phi)$. The second step implies that depending on whether $\gamma+\theta \leq 1$ or $\gamma+\theta>1, E(\Phi)$ is decreasing in $h$ for all $h \in[0,1]$ or hump-shaped. For example, in the first case, $h$ has to fall in order to keep $E(\Phi)$ equal to 1 .

\subsection{Taylor series approximation}

Using the second-order Taylor series expansion around $\bar{\eta}$ implies that

$$
\begin{aligned}
E\left[\frac{\eta}{\left(1+\eta h^{\gamma+\theta}\right)^{\sigma_{f}}}\right] \approx & \frac{\bar{\eta}}{\left(1+\bar{\eta} h^{\gamma+\theta}\right)^{\sigma_{f}}}+ \\
& +\frac{1}{2}\left(\frac{\left(\sigma_{f}+1\right) \sigma_{f} \bar{\eta} h^{2(\gamma+\theta)}}{\left(1+\bar{\eta} h^{\gamma+\theta}\right)^{\sigma_{f}+2}}-\frac{2 \sigma_{f} h^{\gamma+\theta}}{\left(1+\bar{\eta} h^{\gamma+\theta}\right)^{\sigma_{f}+1}}\right) \sigma_{\eta}^{2}
\end{aligned}
$$

where $\sigma_{\eta}^{2}$ represents the variance of $\eta$. Hence, this yields an approximation of the expectation in the BEGP research condition (13), which is used to draw the graphs in figures 1 and 2 .

\subsection{Alternative model}

This version model the model follows the line of reasoning that, since firms are owned by the representative consumer, the utility function of the representative consumer determines how firms behave. ${ }^{10}$ Hence, we assume here that all consumers are the same. As there are infinite many firms, a single firm has no effect on the profit of the representative consumer. We therefore let the representative consumer make all the choices (and, hence, internalizes the external effect of skilled labor). This implies that the representative consumer solves the optimization problem:

$$
\begin{gathered}
\max _{x, h, c} E \sum_{t=0}^{\infty}\left(\frac{1}{1+\rho}\right)^{t} \frac{c_{t}^{1-\sigma}-1}{1-\sigma} \\
\text { s.t. } b_{t+1}=(1+r) b_{t}+w_{t}+\pi_{t}-c_{t},
\end{gathered}
$$

\footnotetext{
${ }^{10}$ In a way, this is similar to Wälde (1999), where firms indirectly, i.e., firms are only engaged in static maximization, maximize the expected utility of the representative consumer.
} 


$$
A_{t+1}=\left(1+\eta_{t+1} h_{t}^{\gamma+\theta}\right) A_{t}
$$

Inserting the expression for $\pi_{t}\left(=\pi_{i t}\right)$ into the budget restriction, the restriction becomes

$$
b_{t+1}=(1+r) b_{t}+Y_{t}-r A_{t} x_{t}-c_{t} .
$$

The first-order condition with respect to $x_{t}$ implies that

$$
r=\beta L_{t}^{1-\beta} A_{t} x_{t}^{\beta-1} .
$$

The first-order condition with respect to $h_{t}$ can be written as

$$
\begin{aligned}
& c_{t}^{-\sigma}\left[-(1-\beta)\left(1-h_{t}\right)^{-\beta} A_{t} x_{t}^{\beta}\right]+ \\
& \frac{1}{1+\rho} E\left\{c_{t+1}^{-\sigma}(\gamma+\theta) \eta_{t+1} h_{t}^{\gamma+\theta-1}\left[\left(1-h_{t+1}\right)^{1-\beta} A_{t} x_{t+1}^{\beta}-r A_{t} x_{t}\right]\right\}=0 .
\end{aligned}
$$

Using both first-order conditions and the fact that on a BEGP $x_{t}=x_{t+1}$ and $h_{t}=h_{t+1}$, the 'alternative' BEGP research condition reads

$$
E\left((\gamma+\theta)(1-h) h^{\gamma+\theta-1} \frac{\eta_{t+1}}{(1+\rho)\left(c_{t+1} / c_{t}\right)^{\sigma}}\right)=1 .
$$

If we compare this equation with the BEGP research condition as given by equation (13) in the text, there are three differences. First, instead of $\gamma$ we have here $\gamma+\theta$, reflecting the fact that the representative consumer internalizes the externalities between the firms. Second, $r$ is replaced by $\rho$, since the consumer discounts time with the time preference, while the firms discount time with the interest rate. Third and most importantly, $1+\eta_{t+1} h_{t}^{\gamma+\theta}$, the growth rate of technology, is replaced by $c_{t+1} / c_{t}$, the growth rate of consumption. While the first two differences do not affect the qualitative effect of uncertainty on growth, the third difference makes it hard (impossible?) to determine the effect of uncertainty on growth in general, since we cannot solve for the growth rate of consumption, ${ }^{11}$ except when the interest rate is exactly that value at which saving equals investment. In the latter case the growth rate of consumption exactly equals the rate of technological change, and equation (24) is qualitatively similar to equation (13) yielding the same result concerning the effect of uncertainty on growth as stated in Proposition 1.

\footnotetext{
${ }^{11}$ Actually, you do not necessarily have to solve for the growth rate of consumption completely. E.g. if the growth rate is a linear function of the shock, the effect of uncertainty is similar as in the model in the text.
} 


\section{References}

[1] AGHION, P. and HOWITT, P. (1998). Endogenous Growth Theory. Cambridge, MA and London, England: The MIT Press.

[2] AIZENMAN, J. and MARION, N. (1999). Volatility and Investment: Interpreting Evidence from Developing Countries. Economica, 66 (262), 1157-79.

[3] BEETSMA, R.M.W.J. and SCHOTMAN, P.C. (2001). Measuring risk attitudes in a natural experiment: data from the television game show lingo. The Economic Journal, 111, 821-48.

[4] BLACKBURN, K. and PELLONI, A. (2001). On the Relationship between Growth and Volatility in Learning-by-Doing Economies. Discussion Paper 001, The University of Manchester.

[5] CAMPBELL, J.Y., LO, A.W. and MACKINLAY, A.C. (1997). The Econometrics of Financial Markets. Princeton, NJ: Princeton University Press.

[6] DE HEK, P.A. (1999). On Endogenous Growth under Uncertainty. International Economic Review, 40, 727-44.

[7] DINOPOUlOS, E. and THOMPSON, P. (1996). A Contribution to the Empirics of Endogenous Growth. Eastern Economic Journal, 22, 389400.

[8] _ and (2000). Endogenous Growth in a Cross-Section of Countries. Journal of International Economics, 51, 335-62.

[9] GERTNER, R. (1993). Game shows and economic behavior: Risk taking on "card sharks". Quarterly Journal of Economics, 108, 507-21.

[10] GUISO, L. and PARIGI, G. (1999). Investment and Demand Uncertainty. Quarterly Journal of Economics, 114, 185-227.

[11] GUVENEN, M.F. (2002). Reconciling Conflicting Evidence on the Elasticity of Intertemporal Substitution: A Macroeconomic Perspective. Unpublished paper, University of Rochester.

[12] HALL, R.E. (1988). Intertemporal Substitution in Consumption. Journal of Political Economy, 96, 339-57. 
[13] HALL, B., GRILICHES, Z. and HAUSMAN, J. (1986). Patents and R\&D. Is there a Lag? International Economic Review, 27, 265-83.

[14] HOPENHAYN, H. and MUNIAGURRIA, M. (1996). Policy Variability and Economic Growth. Review of Economic Studies, 63, 611-25.

[15] JONES, L.E., MANUELLI, R.E. and STACCHETTI, E. (1999). Technology (and Policy) Shocks in Models of Endogenous Growth. NBER Working Paper, no. 7063.

[16] KING, R.G., PLOSSER, C. and REBELO, S.T. (1988). Production, Growth and Business Cycles, II: New Directions. Journal of Monetary Economics, 21, 309-41.

[17] _ and REBELO, S.T. (1988). Business Cycles with Endogenous Growth. Unpublished Paper, University of Rochester.

[18] KORMENDI, R.L. and MEGUIRE, P.G. (1985). Macroeconomic Determinants of Growth: Cross-Country Evidence. Journal of Monetary Economics, 16, 141-63.

[19] KORTUM, S. (1993). Equilibrium R\&D and the Patent-R\&D Ratio: U.S. Evidence. American Economic Review, Papers and Proceedings, 83, 450-7.

[20] LUCAS, R.E., Jr. (1988). On the Mechanics of Economic Development. Journal of Monetary Economics, 22, 3-42.

[21] METRICK, A. (1995). A natural experiment in "jeopardy". American Economic Review, 85, 240-53.

[22] OBSTFELD, M. (1994). Risk-Taking, Global Diversification and Growth. American Economic Review, 84, 1310-29.

[23] RAMEY, G. and RAMEY, V.A. (1995). Cross-Country Evidence on the Link between Volatility and Growth. American Economic Review, 85, 1138-51.

[24] ROMER, P.M. (1986). Increasing Returns and Long-Run Growth. Journal of Political Economy, 94, 1002-37.

[25] _ (1990). Endogenous Technological Change. Journal of Political Economy, 98, S71-S102. 
[26] ROTHSCHILD, M. and STIGLITZ, J.E. (1970). Increasing Risk I: A Definition. Journal of Economic Theory, 2, 225-43.

[27] _ and _ (1971). Increasing Risk II: Its Economic Consequences. Journal of Economic Theory, 3, 66-84.

[28] SANDMO, A. (1971). On the Theory of the Competitive Firm under Price Uncertainty. American Economic Review, 61, 65-73.

[29] THOMPSON, P. (1996). Technological Opportunity and the Growth of Knowledge. Journal of Evolutionary Economics, 6, 77-97.

[30] VIAENE, J.-M. and ZILCHA, I. (1998). The Behavior of Competitive Exporting Firms under Multiple Uncertainty. International Economic Review, 39, 591-609.

[31] VISSING-JØRGENSON, A. (2001). Limited Asset Market Participation and the Elasticity of Intertemporal Substitution. Journal of Political Economy, 110, 825-53.

[32] WÄLDE, K. (1999). A Model of Creative Destruction with Undiversifiable Risk and Optimizing Households. Economic journal, 109, C156C171. 


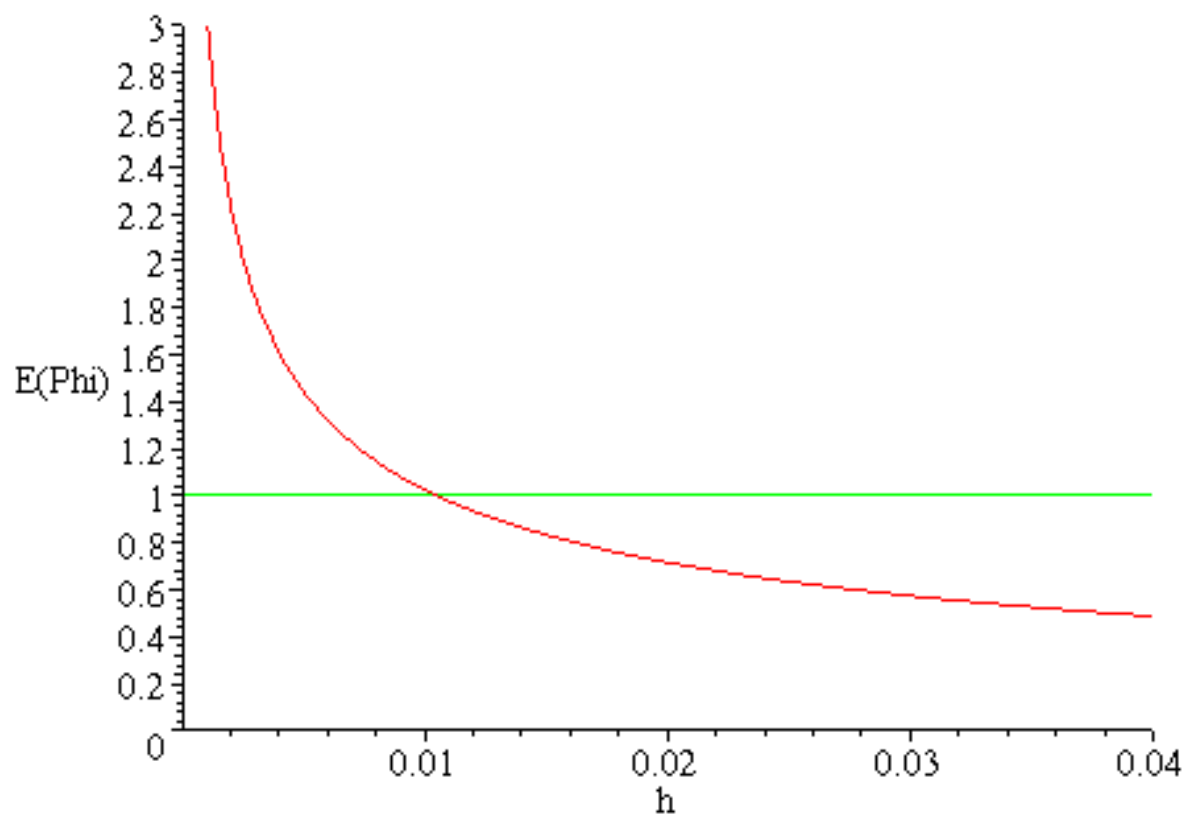

Figure 1: Equilibrium research condition, with $\gamma+\theta \leq 1$. The figure is based on equation (13) where the expectation is approximated with a second-order Taylor series expansion (see appendix). The parameter values are: $\beta=1 / 3$, $\gamma=0.5, \theta=0.05, \rho=0.05, \sigma_{f}=1.25, \bar{\eta}=0.85, \sigma_{\eta}^{2}=0.01$. 


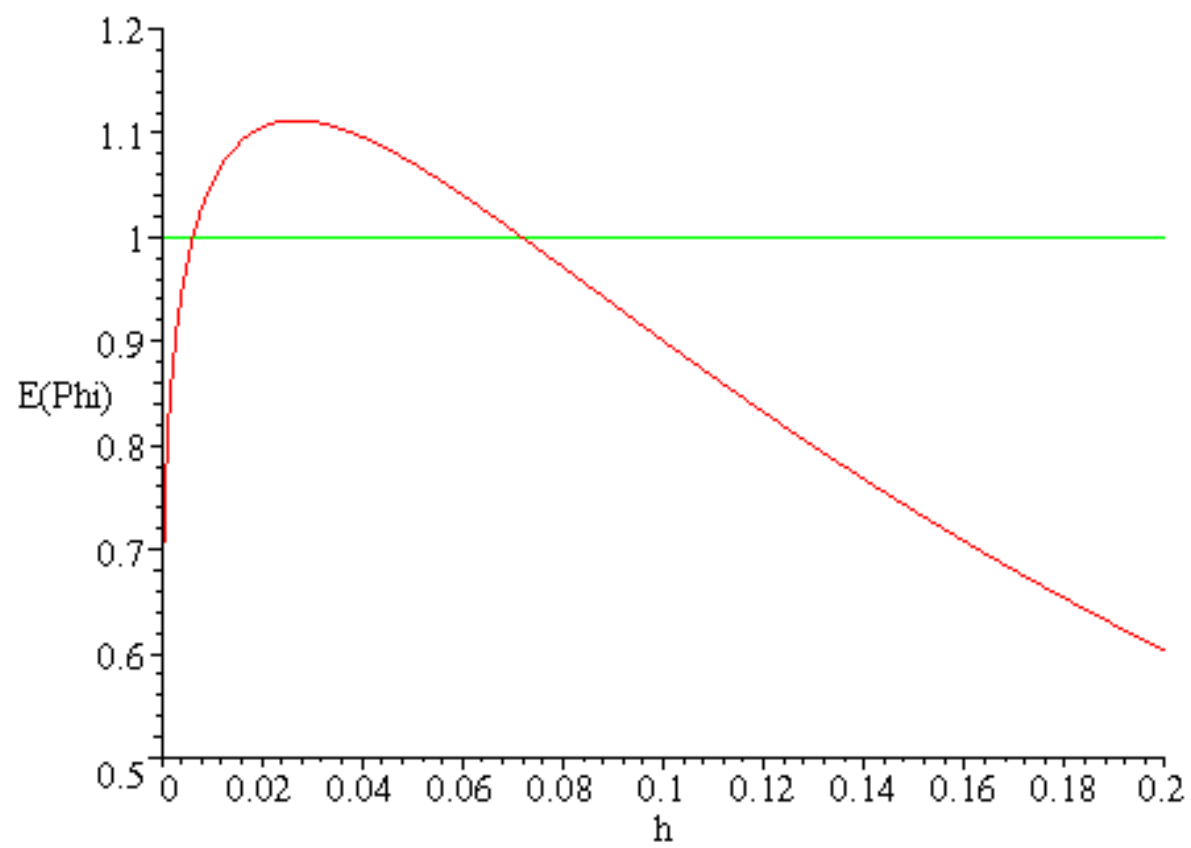

Figure 2: Equilibrium research condition, with $\gamma+\theta>1$. The figure is based on equation (13) where the expectation is approximated with a second-order Taylor series expansion (see appendix). The parameter values are: $\beta=1 / 3$, $\gamma=1.1, \theta=0.05, \rho=0.05, \sigma_{f}=1.25, \bar{\eta}=6, \sigma_{\eta}^{2}=0.01$. 